\title{
Enhanced Enzymatic Preparation of Lipophilic Feruloylated Lipids Using Distearin as Feruloyl Acceptors: Optimization by Response Surface Methodology
}

\author{
Shangde Sun* and Wenya Zhou
}

Lipid Technology and Engineering, School of Food Science and Engineering, Henan University of Technology, Lianhua Road, Zhengzhou 450001, Henan Province, P. R. China

\begin{abstract}
Feruloylated lipids are esters of ferulic acid, which have antioxidation and UV-absorbing activities. In this study, lipophilic feruloylated lipids were prepared by the enzymatic transesterification of ethyl ferulate (EF) with distearin. Effects of different diacylglycerols as feruloyl acceptors were compared. Effects of transesterification variables were studied and optimized using response surface methodology. Under the optimized conditions (reaction temperature $78^{\circ} \mathrm{C}$, reaction time $24 \mathrm{~h}$, and enzyme load $14 \%$ ), EF conversion was $\mathbf{9 7 . 6} \pm \mathbf{2 . 2} \%$, and the lipophilic feruloylated lipids prepared by the transesterification were consisted of $\mathbf{4 3 . 2 \pm 0 . 9 \%}$ feruloylated monoacylglycerols (FMAG) and $33.3 \pm \mathbf{1 . 3} \%$ feruloylated diacylglycerols (FDAG), respectively. Analysis of variance (ANOVA) showed that the regression equation was adequate for predicting the transesterification. The activation energies for the transesterification of EF with distearin to form lipophilic FMAG + FDAG and the side reaction hydrolysis of EF to form glyceryl ferulate + glyceryl diferulate were 57.75 and $40.31 \mathrm{~kJ} / \mathrm{mol}$, respectively.
\end{abstract}

Key words: enzymatic transesterification, distearin, feruloylated monoacylglycerols, feruloylated diacylglycerols, response surface methodology

\section{INTRODUCTION}

Ferulic acid is a recognized natural antioxidant and UVabsorbing substance in most higher plants ${ }^{1,2)}$. However, ferulic acid has poor solubility in lipophilic media, which limites its applications in oil-based food, cosmetics, and other industries. To solve this problem and retain phenolic hydroxyl group and carbon-carbon double bond of ferulic acid, it is necessary to modify carboxyl group in ferulic acid with lipophilic moieties ${ }^{3-9)}$. Feruloylated monoacylglycerols (FMAG) and feruloylated diacylglycerols (FDAG) are lipophilic feruloylated lipids of ferulic acid, which have been used as lipophilic antioxidants and UV absorbers in food and other fields ${ }^{10,11)}$. As ferulic acid is a heat-sensitive phenolic acid and susceptible to oxidation, which makes enzymatic synthesis of FMAG and FDAG become an attractive alternative $^{5,8)}$.

FMAG and FDAG can be prepared by the enzymatic transesterification of ethyl ferulate $(\mathrm{EF})$ or ferulic acid with triacylglycerols $(\mathrm{TAG})^{5,12)}$. But the great stearic hindrance of TAG made the reaction efficiency very low. For enhancing reaction rate, partially deacylated soybean oil was used as feruloyl acceptors ${ }^{13)}$. For further reducing the stearic hindrance effect of feruloyl acceptors on the reaction, a novel enzymatic transesterification of EF with monostearin was developed $^{14)}$. However, in the transesterification product, the content of lipophilic feruloylated lipids (FMAG and FDAG) was low $(36.6 \pm 2.2 \%$ FMAG, $9.1 \pm 2.0 \%$ FDAG). A novel two consecutive enzymatic step route for FMAG and FDAG production was also found in previous report $^{8)}$. But a 10 -fold excess glycerol to EF as reactant and solvent was required to obtain high FMAG and FDAG yields, which led to many by-products monoacylglycerols (MAG) and diacylglycerols (DAG) formed and made FMAG and FDAG purification very difficult. Therefore, more efficient methods for lipophilic FMAG and FDAG preparation have attracted much attention.

In this study, to prepare high-yield FMAG and FDAG, enzymatic tranesterification of EF with distearin was investigated (Fig. 1). Effects of different composition of DAG as feruloyl acceptors on the transesterification were also evalAbbreviations: FMAG, feruloylated monoacylglycerols; FDAG, feruloylated diacylglycerols; EF, ethyl ferulate.

\footnotetext{
* Correspondence to: Shangde Sun, Lipid Technology and Engineering, School of Food Science and Engineering, Henan University of Technology, Lianhua Road, Zhengzhou, Henan, 450001, P. R. China

E-mail: sunshangde@ hotmail.com

Accepted June 16, 2014 (received for review May 18, 2014)

Journal of Oleo Science ISSN 1345-8957 print / ISSN 1347-3352 online

http://www.jstage.jst.go.jp/browse/jos/ http://mc.manusriptcentral.com/jjocs
} 


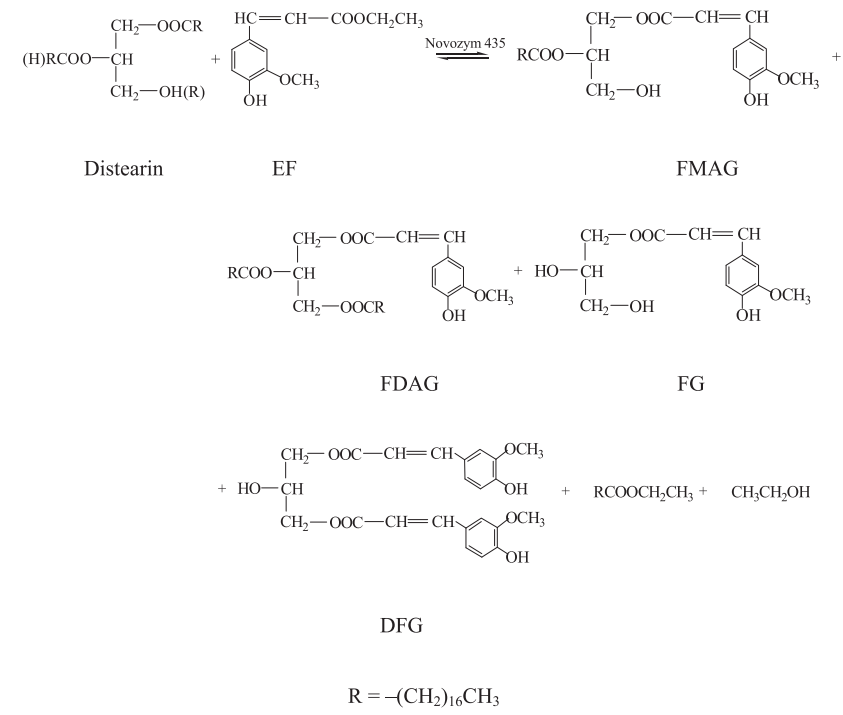

Fig. 1 Enzymatic tranesterification of ethyl ferulate (EF) with distearin to prepare lipophilic feruloylated monoacylglycerols (FMAG) and feruloylated diacylglycerols (FDAG).

uated. Effects of reaction parameters (reaction temperatures, enzyme load, and reaction time) on the transesterification were studied and optimized using response surface methodology. The transesterification of EF with distearin to form lipophilic FMAG + FDAG and side hydrolysis reaction of EF to form hydrophilic glyceryl ferulate $(\mathrm{FG})+$ glyceryl diferulate (DFG) were also studied.

\section{EXPERIMENTAL}

\subsection{Materials}

Novozym 435 (Candida antarctica lipase immobilized on polyacrylic resin by adsorption, 10,000 PLU/g solid enzyme) was purchased from Novozymes A/S (Bagsvaerd, Denmark). Ethyl ferulate(EF, purity $>99 \%$ )was from Suzhou Chang Tong Chemical Co., Ltd (Suzhou, China). Distearin $(16.3 \pm 2.0 \%$ MAG, $44.0 \pm 2.6 \%$ DAG, $37.2 \pm 1.8 \%$ TAG, and $2.5 \pm 1.0 \%$ free fatty acids $)$ and diolein $(21.8 \pm$ $1.9 \% \mathrm{MAG}, 47.3 \pm 2.1 \% \mathrm{DAG}, 25.9 \pm 1.5 \% \mathrm{TAG}$, and $5.0 \pm$ $1.1 \%$ free fatty acids) were purchased from Jinan Dowin Chemical Thechnology Co., Ltd(Jinan, China). Enova oil $(2.0 \pm 0.2 \% \mathrm{MAG}, 86.9 \pm 1.8 \% \mathrm{DAG}$, and $11.1 \pm 1.7 \%$ TAG) was from Kao (China) Holding Co., Ltd (Shanghai, China). Methanol and glacial acetic acid were HPLC grade. All other regents were analytical grade.

\subsection{Enzymatic transesterification procedure}

$\mathrm{EF}$ and distearin (molar ratio of $\mathrm{EF}$ to distearin, 1:1) were added to $25 \mathrm{ml}$ round-bottom flasks, which was incubated in a water bath to required temperature. Then, the immo- bilized lipase was added to the reaction mixtures. Reactions were carried out under $10 \mathrm{~mm} \mathrm{Hg}$ vacuum pressure. Samples $(20 \mu \mathrm{l})$ were withdrawn at specified time intervals.

\subsection{HPLC analysis}

The reactants and products were analyzed by HPLC and HPLC-ESI-MS according to the previous reports ${ }^{8,15)}$.

\subsection{Response surface design}

A 3-level-3-factor Box-Behnken response surface design was performed to investigate the effect of reaction variables on the transesterification. The factors and levels selected were as follows: reaction time $(4,20,36 \mathrm{~h})$, reaction temperature $\left(70,90,110^{\circ} \mathrm{C}\right)$, enzyme load $(5 \%, 10 \%, 15 \%$; relative to the weight of total substrates) (Table 1).

\subsection{Statistical analysis}

The experiments were carried out for analysis using design expert. For the present study, a total of 17 tests were necessary to estimate the coefficients. The mathematical relationship relating the variables to the responses can be calculated by the quadratic polynomial equation:

$$
Y=\beta_{o}+\sum_{i=1}^{3} \beta_{i} X_{i}+\sum_{i=1}^{3} \beta_{i i} X_{i}^{2}+\sum_{i=1}^{3} \sum_{j=i+1}^{3} \beta_{i j} X_{i} X_{j}
$$

where $Y$ is the response (EF conversion or FMAG + FDAG yield); $X_{i}$ and $X_{j}$ are the independent variables; $\beta_{0}, \beta_{i}, \beta_{i i}$, and $\beta_{i j}$ are the constant coefficients.

\section{RESULTS AND DISCUSSION}

\subsection{Effect of different diacylglycerols as feruloyl acceptors}

Figure 2 shows the effect of different diacylglycerols (distearin, diolein, and Enova oil) as feruloyl acceptors on the transesterification. Using Enova oil as feruloyl acceptors, $\mathrm{EF}$ conversion was $75.9 \pm 2.0 \%$ at $48 \mathrm{~h}$, which was lower than that $(97.5 \pm 1.8 \%$ and $99.1 \pm 0.8 \%)$ of distearin and diolein. However, using distearin and diolein as feruloyl acceptors, EF conversions rapidly increased, which were faster than that of Enova oil. EF conversions of distearin and diolein were both higher than those $(<90 \% \mathrm{EF}$ conversion at $144 \mathrm{~h}$ ) of previous reports using soybean oil and partially deacylated soybean oil as feruloyl acceptors ${ }^{5,13)}$, which may be attributed to little steric hindrance of distearin and diolein and efficiency removal of by-product ethonal using vacuum from the transesterification system. In the transesterification products of $48 \mathrm{~h}$ using distearin and diolein as feruloyl acceptor, the lipophilic FMAG + FDAG yields were $75.7 \pm 2.1 \%$ and $72.8 \pm 1.1 \%$, respectively, which were higher than that $(45.7 \pm 2.2 \%)$ using monostearin as feruloyl acceptor ${ }^{14)}$. These differences can be ascribed to more fatty acyls of distearin than that of monostearin. The lipophilic feruloylated lipids formed using distearin as feruloyl acceptor were consisted of 45.2 
Table 1 Experimental design and results of transesterification of ethyl ferulate (EF) and distearin affected by reaction temperature, reaction time, and enzyme load.

\begin{tabular}{crrrrr}
\hline $\begin{array}{c}\text { Treament } \\
\text { no. }\end{array}$ & $\begin{array}{c}\text { Reaction } \\
\text { Temperature } \\
X_{1}\left({ }^{\circ} \mathrm{C}\right)\end{array}$ & $\begin{array}{c}\text { Reaction } \\
\text { Time } \\
X_{2}(\mathrm{~h})\end{array}$ & $\begin{array}{c}\text { Enzyme } \\
\text { load } \\
X_{3}(\%)\end{array}$ & $\begin{array}{c}\text { EF conversion } \\
(\%)\end{array}$ & $\begin{array}{c}\text { FMAG + FDAG } \\
\text { yields }(\%)\end{array}$ \\
\hline 1 & $-1(70)$ & $1(36)$ & $0(10)$ & $95.0 \pm 1.2 \%$ & $69.8 \pm 1.5 \%$ \\
2 & $0(90)$ & $0(20)$ & $0(10)$ & $97.2 \pm 1.0 \%$ & $79.7 \pm 1.3 \%$ \\
3 & $0(90)$ & $0(20)$ & $0(10)$ & $98.0 \pm 0.7 \%$ & $81.0 \pm 0.5 \%$ \\
4 & $0(90)$ & $-1(4)$ & $1(15)$ & $87.8 \pm 1.5 \%$ & $66.7 \pm 1.5 \%$ \\
5 & $-1(70)$ & $0(20)$ & $1(15)$ & $95.2 \pm 0.8 \%$ & $71.6 \pm 0.6 \%$ \\
6 & $1(110)$ & $0(20)$ & $1(15)$ & $96.1 \pm 1.5 \%$ & $79.5 \pm 0.9 \%$ \\
7 & $1(110)$ & $1(36)$ & $0(10)$ & $92.8 \pm 1.6 \%$ & $79.3 \pm 1.2 \%$ \\
8 & $1(110)$ & $0(20)$ & $-1(5)$ & $75.3 \pm 1.0 \%$ & $63.9 \pm 1.1 \%$ \\
9 & $1(110)$ & $-1(4)$ & $0(10)$ & $77.5 \pm 1.2 \%$ & $61.9 \pm 1.4 \%$ \\
10 & $0(90)$ & $0(20)$ & $0(10)$ & $91.5 \pm 2.5 \%$ & $71.4 \pm 1.7 \%$ \\
11 & $0(90)$ & $0(20)$ & $0(10)$ & $96.8 \pm 1.1 \%$ & $76.8 \pm 0.7 \%$ \\
12 & $0(90)$ & $0(20)$ & $0(10)$ & $97.1 \pm 0.9 \%$ & $77.1 \pm 0.6 \%$ \\
13 & $-1(70)$ & $-1(4)$ & $0(10)$ & $52.1 \pm 2.5 \%$ & $33.8 \pm 1.9 \%$ \\
14 & $-1(70)$ & $0(20)$ & $-1(5)$ & $78.9 \pm 1.3 \%$ & $56.3 \pm 0.9 \%$ \\
15 & $0(90)$ & $1(36)$ & $-1(5)$ & $97.2 \pm 1.5 \%$ & $79.0 \pm 1.4 \%$ \\
16 & $0(90)$ & $-1(4)$ & $-1(5)$ & $64.7 \pm 0.9 \%$ & $46.9 \pm 1.3 \%$ \\
17 & $0(90)$ & $1(36)$ & $1(15)$ & $99.3 \pm 0.5 \%$ & $72.1 \pm 0.5 \%$ \\
\hline
\end{tabular}

${ }^{a}$ Numbers were run in random order.

${ }^{\mathrm{b}}$ Enzyme load (w/w, relative to the weight of total substrates).

${ }^{\mathrm{c}} \mathrm{FMAG}$, feruloylated monoacylglycerols; FDAG, feruloylated diacylglycerols.

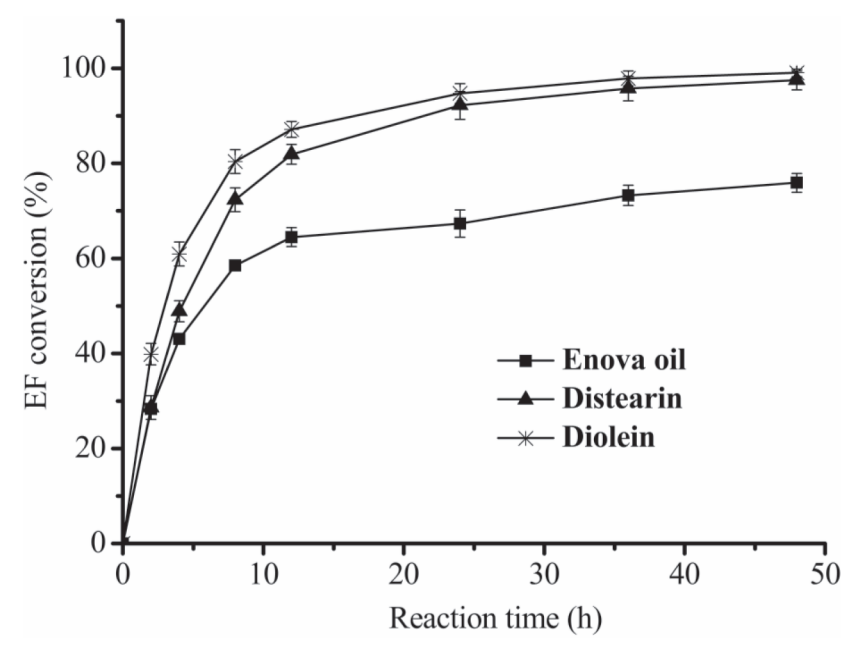

Fig. 2 Effects of different diacylglycerols as feruloyl acceptors on the transesterification. Reaction conditions: 1:1 molar ratio of EF to feruloyl acceptor, enzyme load $10 \%$ (relative to the weight of total substrates), $70^{\circ} \mathrm{C}$. $\pm 1.5 \%$ FMAG and $30.5 \pm 1.2 \%$ FDAG. Therefore, considering FMAG and FDAG yields and the cost of feruloyl acceptors, distearin was best choice for the transesterification.

\subsection{Effect of reaction system pressure}

Under atmosphere pressure or $10 \mathrm{~mm} \mathrm{Hg}$ vacuum, EF conversions rapidly increased to $67.6 \pm 2.1 \%$ and $81.9 \pm$ $1.7 \%$, respectively, in $12 \mathrm{~h}$. However, the maximum EF conversion $(97.5 \pm 1.8 \%)$ using $10 \mathrm{~mm} \mathrm{Hg}$ vacuum was higher than that $(83.6 \pm 2.0 \%)$ of atmosphere pressure. Using $10 \mathrm{~mm} \mathrm{Hg}$ vacuum in the reaction system, the yield ratio of FMAG + FDAG to FG + DFG was 1 to 3-fold higher than that of atmosphere pressure. These results can be ascribed to the fact that, the by-product (ethanol) formed by the transesterification of EF and DAG can be easily removed from reaction system under $10 \mathrm{~mm} \mathrm{Hg}$ vacuum, which make the transesterification equilibrium move toward FMAG + FDAG preparation. Thus, $10 \mathrm{~mm} \mathrm{Hg}$ vacuum system was used in the subsequent experiments.

\subsection{Effects of reaction variables}

Due to high melting points of $\operatorname{EF}\left(63-65^{\circ} \mathrm{C}\right)$ and distearin 
(a)

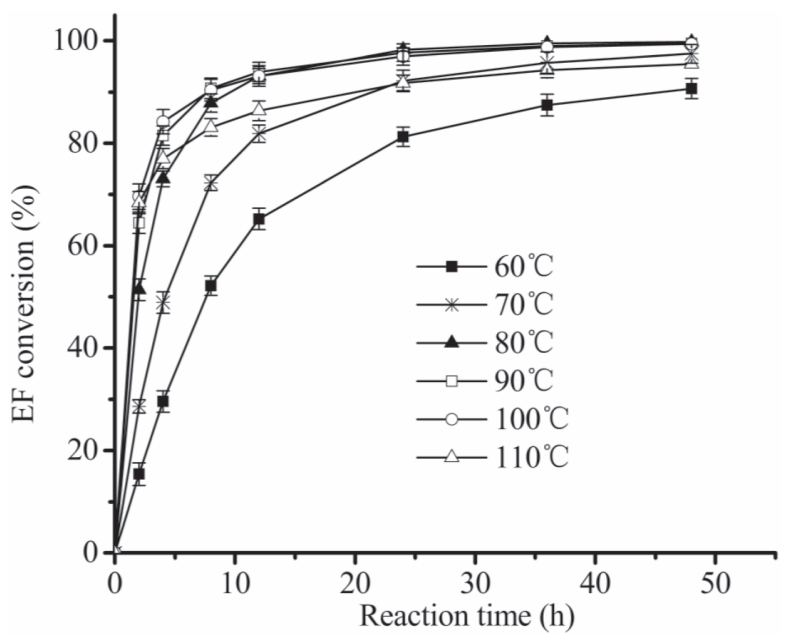

(b)

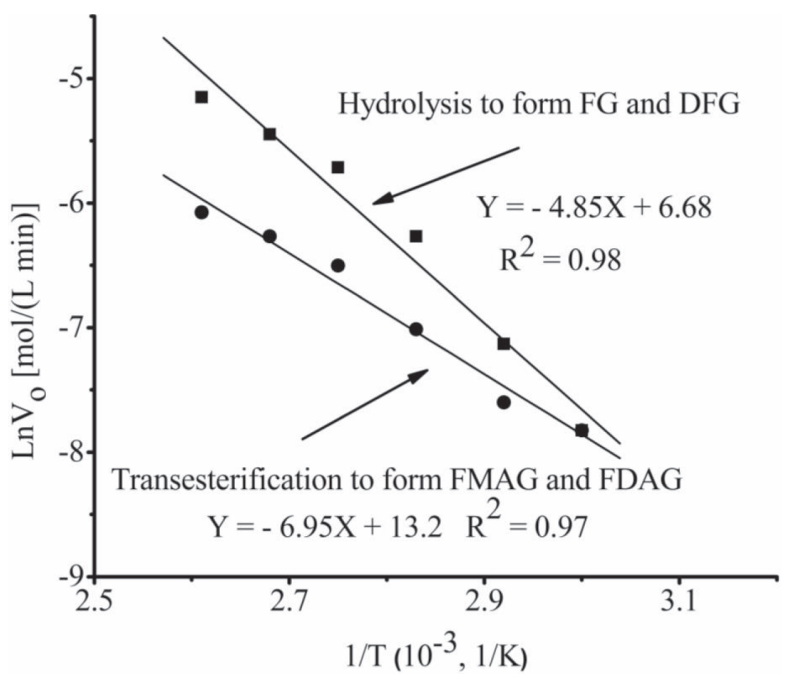

(c)

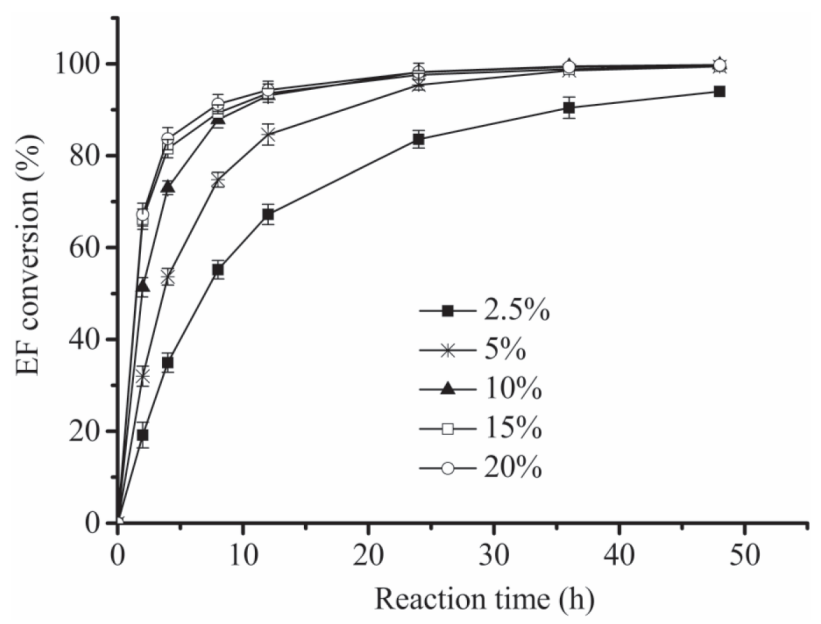

(d)

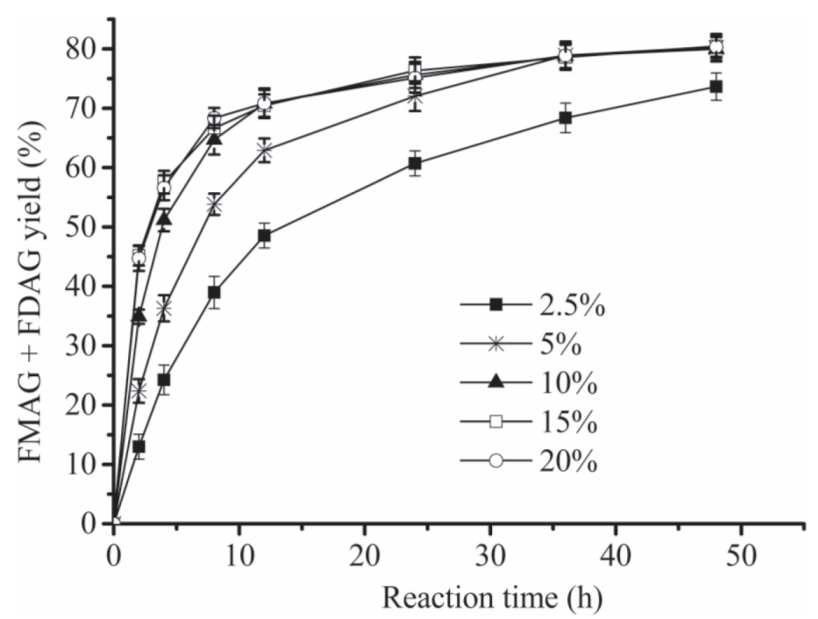

Fig. 3 (a) Effect of reaction temperature on EF conversion. Reaction conditions: 1:1 molar ratio of EF to distearin, enzyme load $10 \%$ (relative to the weight of total substrates). (b) The relationship between the initial hydrolysis rate of EF to form hydrophilic FG + DFG or transesterification rate of EF with distearin to form FMAG + FDAG and reaction temperature. Reaction conditions were same as (a). Effect of enzyme load on EF conversion (c) and FMAG + FDAG yield (d). Reaction conditions: 1:1 molar ratio of EF to distearin, $80^{\circ} \mathrm{C}$.

$\left(71-74^{\circ} \mathrm{C}\right)$, high reaction temperatures were required in the studies. The lowest reaction temperature was set at $60^{\circ} \mathrm{C}$ to avoid mass transfer limitation and enhance reaction rate. With the increase of reaction temperature from $60^{\circ} \mathrm{C}$ to $100^{\circ} \mathrm{C}, \mathrm{EF}$ conversion and transesterification rate increased (Fig. 3a). However, at $110^{\circ} \mathrm{C}$, EF conversion decreased, which was attributed to the deactivation of Novozym 435 at higher temperatures. The initial reaction rates $\left(V_{0}, \mathrm{~mol} /(\mathrm{L} \cdot \mathrm{min})\right)$, defined as the initial $\mathrm{EF}$ conversion or FMAG + FDAG formation (FG + DFG formation) per unit time, were calculated from six experimental points of $\mathrm{EF}$ conversion (or FMAG + FDAG, FG + DFG formation) time profile corresponding to the first $1 \mathrm{~h}$ of the reaction
(15.0\% or less EF conversion), where the profiles were found to be approximately linear. With the increase of reaction temperature, the ratio of lipophilic FMAG + FDAG to hydrophilic FG + DFG increased, which can be explained that by the fact that, the activation energy $(57.75 \mathrm{~kJ} / \mathrm{mol})$ of transesterification of EF with distreain to form FMAG and FDAG was higher than that $(40.31 \mathrm{~kJ} / \mathrm{mol})$ of side reaction hydrolysis to form FG and DFG(Fig. 3b). These activation energies of transesterification and hydrolysis were both higher than those (51.05 and $22.45 \mathrm{~kJ} / \mathrm{mol}$ ) using monostearin as feruloyl acceptor ${ }^{14)}$, which was ascribed to greater steric hindrance of distearin than that of monostearin.

When enzyme load was less than $10 \%$, with the increase 
Table 2 ANOVA analysis of quadratic models for the EF conversion and FMAG + FDAG yield.

\begin{tabular}{lrrrrc}
\hline \multicolumn{1}{c}{ Source } & Sum of squares & Degree of freedom & Mean square & F value & Prob $>$ F \\
\hline EF conversion & & & & & \\
\hline Model & 2791.75 & 9 & 311.27 & 14.08 & $<0.01$ \\
Residual & 154.24 & 7 & 22.03 & & \\
Lack of Fit & 127.06 & 3 & 42.35 & 6.23 & 0.06 \\
Pure error & 27.17 & 4 & 6.79 & & \\
Total & 2945.98 & 16 & & & \\
$\mathrm{R}^{2}=0.9476$ & & & & & \\
\hline FMAG + FDAG yield & & & & \\
\hline Model & 2507.08 & 9 & 278.56 & 10.38 & $<0.01$ \\
Residual & 187.80 & 9 & 26.83 & & \\
Lack of Fit & 133.60 & 5 & 44.53 & 3.29 & 0.14 \\
Pure error & 54.20 & 4 & 13.55 & & \\
Total & 2694.87 & 16 & & & \\
$\mathrm{R}^{2}=0.9303$ & & & & & \\
\hline
\end{tabular}

of enzyme load, initial transesterification rate showed a rapid linear growth (Fig. 3c). However, when enzyme load exceeded $10 \%$, EF conversion almost maintained the maximum level $(98.0 \pm 1.3 \%)$ at $24 \mathrm{~h}$. And the reaction time to approach equilibrium shortened from $48 \mathrm{~h}$ of $2.5 \%$ enzyme load to $24 \mathrm{~h}$ of $10 \%$. With the increase of enzyme load, the lipophilic FMAG + FDAG yield also increased from $60.7 \pm 2.1 \%$ of $2.5 \%$ to $75.6 \pm 2.2 \%$ of $10 \%$ at $24 \mathrm{~h}$ (Fig. 3d). Considering the immobilized biocatalyst agglomeration and possible diffusional problems, $10 \%$ enzyme load was selected for the next experiments.

\subsection{Model fitting}

Models of the factors and the responses were performed by response surface methodology to predict the highest possible EF conversion and FMAG + FDAG yield. The results obtained from response surface methodology were listed in Table 1. According to the statistical method, the data were analyzed employing a multiple regression technique to evaluate the true relationship between reaction variables and the responses (EF conversion and FMAG + FDAG yield). The analysis of variance (ANOVA) indicated that the quadratic regression models were significant $(p<$ 0.01 ) and lacks of fit were insignificant (Table 2), which suggested that the models were prominent and adequate to explain the actual relationship between the responses and the significant variables, with a satisfactory coefficient of determination. The values of $\mathrm{R}$-squared indicated the models are suitable to represent the relationships among the selected factors. As a result, the models for EF conversion and FMAG + FDAG yield were successfully established.
$C_{E F}$ and $Y_{F M A G+F D A G}$ are the predicted values for $\mathrm{EF}$ conversion (\%) and FMAG + FDAG yield (\%) and $X_{1}, X_{2}$, and $X_{3}$ are the coded variables as described in Table 1.

$$
\begin{aligned}
& C_{E F}=96.12+2.58 X_{1}+12.78 X_{2}+7.78 X_{3}-6.87 X_{1} X_{2}+ \\
& 1.15 X_{1} X_{3}-5.25 X_{2} X_{3}-8.85 X_{1}^{2}-7.95 X_{2}^{2}-0.89 X_{3}^{2} \\
& Y_{F M A G+F D A G}= 77.21+6.62 X_{1}+11.37 X_{2}+5.48 X_{3}-4.66 X_{1} X_{2} \\
&+0.098 X_{1} X_{3}-6.69 X_{2} X_{3}-7.16 X_{1}^{2}-8.84 X_{2}^{2} \\
&-2.21 X_{3}^{2}
\end{aligned}
$$

Figure $4 \mathrm{a}$ and $4 \mathrm{~b}$ show the effect of reaction time, reaction temperature, and their mutual interaction on EF conversion and FMAG + FDAG yield. The maximum EF conversion appeared in the temperature range of $75-95^{\circ} \mathrm{C}$ and time range of 24-36 h. However, the maximum FMAG + FDAG yield appeared in the temperature range of $92-100^{\circ} \mathrm{C}$ and time range of $24-30 \mathrm{~h}$, which may be ascribed to the fact that high temperature can be beneficial to FMAG + FDAG formation. Figure $4 \mathrm{c}$ and $4 \mathrm{~d}$ show the effect of reaction temperature, enzyme load, and their mutual interaction on EF conversion and FMAG + FDAG yield. At the same enzyme load, with the increase of reaction temperature, EF conversion and FMAG + FDAG yield firstly increased, and then decreased, which was attributed to lipase deactivation at higher reaction temperatures. Figure $4 \mathrm{e}$ and $4 \mathrm{f}$ show the effect of reaction time, enzyme load, and their mutual interaction on EF conversion and FMAG + FDAG yield. Longer reaction time or higher enzyme load led to higher EF conversion, and the maximum FMAG + FDAG yield appeared in the enzyme load ranging from $10 \%$ to $15 \%$ and longer reaction time (> $20 \mathrm{~h}$ ). The analysis of ANOVA also shows that the orders of 
(a)

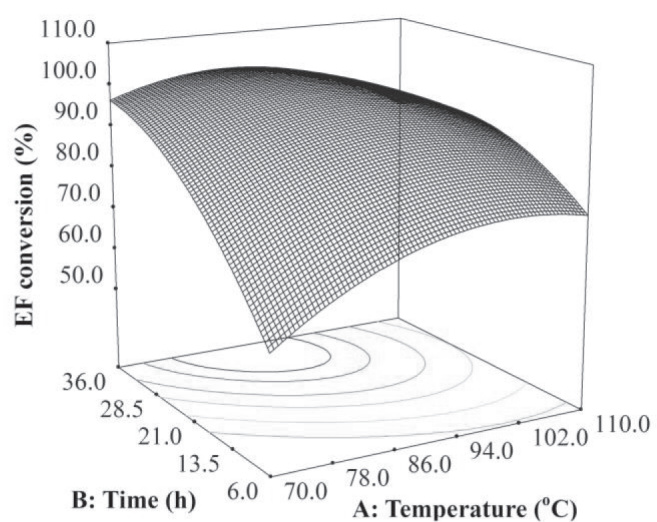

(b)

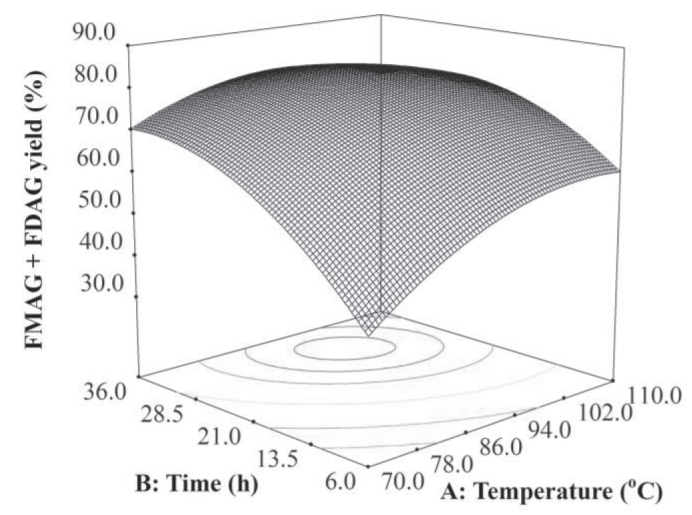

(c)

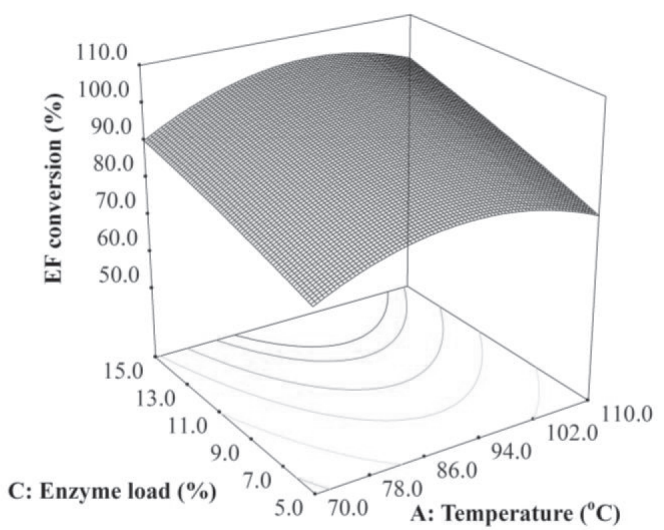

(d)

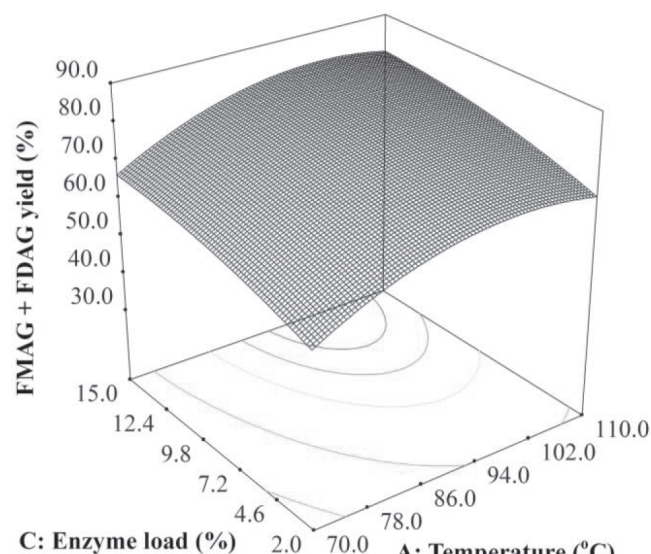

(e)

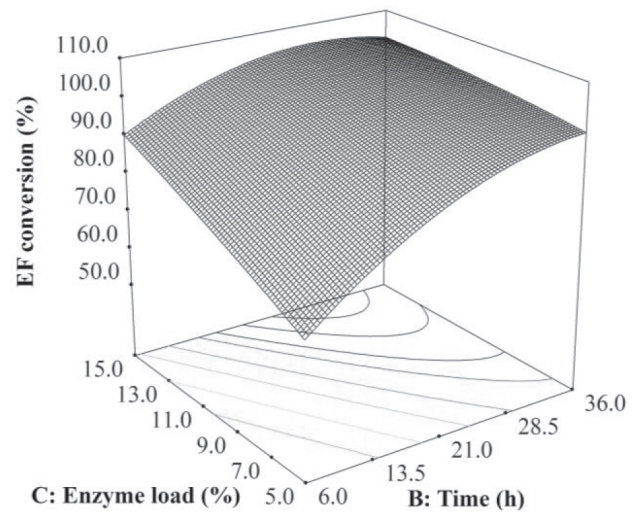

(f)

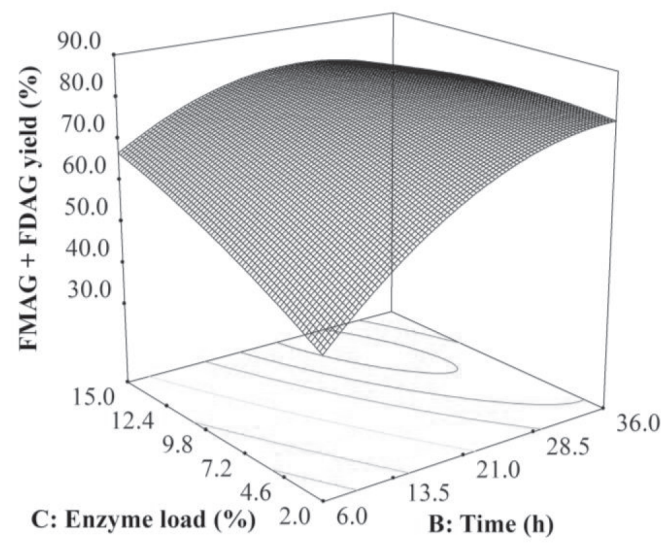

Fig. 4 3D surface plots showing the effect of reaction temperature, reaction time, and their interaction on EF conversion (a) and FMAG + FDAG yield (b) with 10\% enzyme load (relative to the weight of total substrates). 3D surface plots showing the effect of reaction temperature, enzyme load, and their interaction on EF conversion (c) and FMAG + FDAG yield (d) at $20 \mathrm{~h}$. 3D surface plots showing the effect of reaction time, enzyme load, and their interaction on EF conversion (e) and FMAG + FDAG yield (f) at $90^{\circ} \mathrm{C}$.

reaction variables affecting on EF conversion and FMAG + FDAG yield were reaction time $>$ enzyme load $>$ reaction temperature and reaction time $>$ reaction temperature $>$ enzyme load, respectively.

\subsection{Optimum reaction variables and model verfication}

Reaction variables were optimized by response surface methodology as follows: enzyme load 14\%, temperature $78^{\circ} \mathrm{C}$, and reaction time $24 \mathrm{~h}$. Under these conditions, EF 
conversion $(97.6 \pm 2.2 \%)$ was well accorded with the predicted result (99.9\%), which indicated that the model developed was considered to be accurate and reliable. Under these conditions, the transesterification products were consisted of $9.4 \pm 1.1 \% \mathrm{FG}, 11.13 \pm 0.7 \%$ DFG, $43.2 \pm 0.9 \%$ FMAG, and $33.3 \pm 1.3 \%$ FDAG, respectively.

The lipophilic FMAG + FDAG yield $(76.5 \pm 2.2 \%)$ was similar with that $(77 \%)$ of Compton et al. report ${ }^{5)}$. However, EF conversion $(97.6 \pm 2.2 \%)$ was higher than that $(<90 \%)$ of previous reports, reaction time $(24 \mathrm{~h})$ to approach equilibrium was about one sixth of that (144 h) of Compton et al. report ${ }^{5)}$, and the substrate molar ratio of $\mathrm{EF}$ to distearin was $1: 1$, which was lower than that (EF/triolein, 1:3) of previous report ${ }^{12)}$.

\section{CONCLUSION}

A novel feruloyl acceptor (distearin) was successfully used for the enzymatic preparation of lipophilic FMAG + FDAG in solvent-free system. Response surface methodology was used to model and optimize the effect of reaction variables (enzyme load, temperature, and reaction time) on the transesterification of $\mathrm{EF}$ and distearin. The optimized conditions were as follows: enzyme load $14 \%$ (w/w, relative to the weight of substrates), reaction temperature $78^{\circ} \mathrm{C}$, reaction time $24 \mathrm{~h}$. Under these conditions, EF conversion and lipophilic FMAG + FDAG yield were $97.6 \pm 2.2 \%$ and $76.5 \pm 2.2 \%$, respectively; and the lipophilic FMAG + FDAG yield was $76.5 \pm 2.2 \%$. The activation energies for the transesterification of $\mathrm{EF}$ with distearin to form lipophilic FMAG + FDAG and the side reaction hydrolysis of EF to form FG and DFG were 57.75 and $40.31 \mathrm{~kJ} / \mathrm{mol}$, respectively.

\section{ACKNOWLEDGMENTS}

The authors gratefully acknowledge financial support from National Natural Science Foundation of China (31101301), Funding Scheme for Young Teachers in Colleges and Universities in Henan Province(2012GGJS-83), and the Science Research Foundation of Henan University of Technology Graduate Education Innovation Project (2012YJCX15).

\section{References}

1) Kikuzaki, H.; Hisamoto, M.; Hirose, K. Antioxidant properties of ferulic acid and its related compounds. $J$. Agric. Food Chem. 50, 2161-2168(2002).

2) Saija, A.; Tomaino, A.; Cascio, R. L.; Trombetta, D.; Proteggente, A.; Pasquale, A. D.; Uccella, N.; Bonina, F.
Ferulic and caffeic acids as potential protective agents against photooxidative skin damage. J. Sci. Food Agric. 79, 476-480 (1999).

3) Anselmi, C.; Centini, M.; Granata, P.; Sega, A.; Buonocore, A.; Bernini, A.; Facino, R. M. Antioxidant activity of ferulic acid alkyl esters in a heterophasic system: a mechanistic insight. J. Agric. Food Chem. 52, 6425$6432(2004)$.

4) Chen, B.; Liu, H.; Guo, Z.; Huang, J.; Wang, M.; Xu, X.; Zheng, L. Lipase-catalyzed esterification of ferulic acid with oleyl alcohol in ionic liquid/isooctane binary systems. J. Agric. Food Chem. 59, 1256-1263(2011).

5) Compton, D. L.; Laszlo, J. A.; Berhow, M. A. Lipasecatalyzed synthesis of ferulate esters. J. Am. Oil Chem. Soc. 77, 513-519(2000).

6) Jakovetić, S. M.; Jugović, B. Z.; Gvozdenović, M.M.; Bezbradica, D. I.; Antov, M. G.; Mijin, D. Ž.; KneževićJugović, Z. D. Synthesis of Aliphatic Esters of Cinnamic Acid as Potential Lipophilic Antioxidants Catalyzed by Lipase B from Candida antarctica. Appl. Biochem. Biotechnol. 170, 1560-1573(2013).

7) Sorour, N.; Karboune, S.; St-Louis, R.; Kermasha, S. Lipase-catalyzed synthesis of structured phenolic lipids in solvent-free system using flaxseed oil and selected phenolic acids as substrates. J. Biotechnol. 158, 128-136 (2012).

8) Sun, S.; Shan, L.; Liu, Y.; Jin, Q.; Wang, X.; Wang, Z. A novel, two consecutive enzymatic step route for synthesis of feruloylated monoacyl- and diacylglycerols in a solvent-free system. Biotechnol. Lett. 29, 1947-1950 (2007).

9) Yoshida, Y.; Kimura, Y.; Kadota, M.; Tsuno, T.; Adachi, S. Continuous synthesis of alkyl ferulate by immobilized Candida antarctica lipase at high temperature. Biotechnol. Lett. 28, 1471-1474(2006).

10) Compton, D. L. Sunscreens based on vegetable oil. Lipid Technol. 17, 276-279(2005).

11）Laszlo, J. A.; Evans, K. O.; Vermillion, K. E.; Appell, M. Feruloyl dioleoylglycerol antioxidant capacity in phospholipid vesicles. J. Agric. Food Chem. 58, 5842-5850 (2010).

12) Sabally, K.; Karboune, S.; St-Louis, R.; Kermasha, S. Lipase-catalyzed transesterification of trilinolein or trilinolenin with selected phenolic acids. J. Am. Oil Chem. Soc. 83, 101-107 (2006).

13) Laszlo, J. A.; Compton, D. L. Enzymatic glycerolysis and transesterification of vegetable oil for enhanced production of feruloylated glycerols. J. Am. Oil Chem. Soc. 83, 765-770 (2006).

14) Sun, S.; Song, F.; Bi, Y.; Yang, G.; Liu, W. Solvent-free enzymatic transesterification of ethyl ferulate and monostearin: optimized by response surface methodology. J. Biotechnol. 164, 340-345 (2012).

15) Sun, S.; Shan, L.; Liu, Y.; Jin, Q.; Zhang, L.; Wang, X. 
S. Sun, W. Zhou

Solvent-free enzymatic preparation of ferulated mono-

ogy. J. Agric. Food Chem. 56, 442-447 (2008). acylglycerols optimized by response surface methodol- 